\title{
Análises morfométrica e morfológica das alterações cutâneas após uso do laser Nd-YAG em tecidos palpebrais humanos
}

Primeira submissão em 29/10/03 Ultima submissão em 21/11/03 Aceito para publicação em 21/11/03 Publicado em 20/06/04

\section{Cutaneous changes morphometrical and histological analysis after the use of laser Nd-YAG in human eyelid tissue}

\author{
Lúcia de Noronha'; Mariana Jorge Garcia²; Luciane Choppa do Valle³; Eduardo Wei Kin Chin; Letícia Yurie Kimura4; Ruth Graff ${ }^{5}$
}

\section{unitermos \\ Laser Nd-YAG}

Rejuvenescimento facial

Cool Touch

\section{resumo}

$\mathrm{O}$ uso do laser neodymium-yttrium-aluminium-garnet (Nd-YAG) como instrumento auxiliar para o rejuvenescimento propiciou um refinamento da técnica tradicional. Tal procedimento mostra resultados satisfatórios com relação ao aprimoramento técnico e à recuperação pós-operatória. Objetivo: Evidenciar as alterações histológicas e morfométricas encontradas na pálpebra de humanos após aplicação do laser Nd-YAG e comparar com a pele normal. Material e método: Nove pacientes do sexo feminino foram submetidas à aplicação do laser $\mathrm{Nd}$-YAG em região palpebral direita. A pálpebra esquerda correspondeu à área controle, livre de qualquer tipo de procedimento. Foram realizadas várias aplicações do laser Nd-YAG, sendo que, no último dia, foi realizada biópsia palpebral bilateralmente. Os critérios morfométricos avaliados foram: medida da espessura da epiderme, da área subepidérmica livre de lesão, da zona de degeneração do colágeno e da espessura total da derme. Resultados: Nas áreas submetidas à aplicação do laser Nd-YAG, a espessura média da epiderme foi de 33,53 micrômetros $(\mu \mathrm{m})$ e a da pele normal foi de $29,61 \mu \mathrm{m}(p=0,1099)$. A média da medida da área subepidérmica livre de lesão, no lado direito, foi de $40,93 \mu \mathrm{m}$, e de $36,27 \mu \mathrm{m}(p=0,1373)$ no esquerdo. A espessura da região de

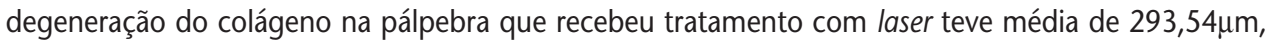
enquanto que na pálpebra normal ela foi de 292,22 $\mu \mathrm{m}(p=0,4835)$. No lado onde se aplicou o laser Nd-YAG, a espessura total da derme teve uma média de $681,48 \mu \mathrm{m}$ e, no lado livre de procedimento, $664,14 \mu \mathrm{m}(p=0,3492)$. Discussão e conclusões: Apesar da diferença clínica observada após tratamento de lesões de envelhecimento em pálpebra de humanos com o uso do laser Nd-YAG, nota-se que não houve diferença histológica ou morfométrica após tal procedimento.

The use of laser Neodymium-Yttrium-Aluminium-Garnet (Nd-YAG) as an auxiliary tool on rejuvenation provided a refining of the traditional technique. This laser procedure show satisfactory results with technical improvement and postoperatory recovery. Objectives: The aim of this study is to show the histological and morphometrical changes found in human eyelid tissue after the use of laser Nd-YAG and its comparision to the normal structure. Material and methods: Nine female patients underwent laser Nd-YAG application on their right eyelid. The left eyelid was taken by control-tissue, free of any kind of procedure. It was made many applications of the laser and on the last day, it was made a bilateral biopsy. The morphometrical criteria appraised were: epidermal denseness measure, subepidermal area free of injury, colagen degeneration and total dermal density. Results: In those areas whose underwent laser the epidermal measure was of 33,53 micrometers $(\mu \mathrm{m})$ and on the normal tissue, was of $29.61 \mu \mathrm{m}(\mathrm{p}=0.1099)$. The subepidermal measure was, on average, of $40.93 \mu \mathrm{m}$ on right side and of $36.27 \mu \mathrm{m}$ on left side $(p=0.1373)$. The colagen degeneration measure on the right side was of $293.54 \mu \mathrm{m}$ and on the left side was of $292.22 \mu \mathrm{m}(\mathrm{p}=0.4835)$. On the procedure site, the total dermal measure was of $681,48 \mu \mathrm{m}$ and on

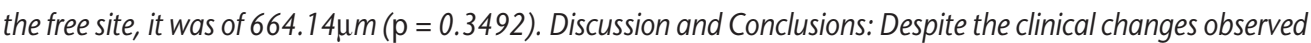
after laser Nd-YAG therapy, there were neither histological nor morphometrical significative changes.

\footnotetext{
1. Professora-assistente da disciplina de Patologia da Pontifícia Universidade Católica do Paraná (PUCPR); doutora em Dermatopatologia.

2. Estudante de Medicina da PUCPR; bolsista do Programa Institucional de Bolsas de Iniciação Científica do Conselho Nacional de Desenvolvimento Científico e Tecnológico (Pibic/CNPq).

3. Estudante de Medicina da PUCPR.

4. Médicos-residentes da PUCPR.

5. Cirurgiã plástica; titular da Sociedade Brasileira de Cirurgia Plástica (SBCP).
} 


\section{Introdução}

Na observação das queixas de pacientes que procuram as clínicas de cirurgia plástica e estética, é fato concreto o anseio na busca por métodos menos invasivos para a obtenção do rejuvenescimento. Muitas técnicas são empregadas com este objetivo. Recentemente, a terapia a laser somou-se ao grupo dos armamentos terapêuticos para o resurfacing e a eliminação de lesões pigmentares. Neste grupo incluem-se: dermabrasão, peeling químico e eletrofulguração, entre outros.

$\mathrm{Na}$ linha evolutiva do tratamento com laser, propõe-se atualmente o laser neodymium-yttrium-aluminium-garnet (Nd-YAG) para o rejuvenescimento facial. Quando comparado às técnicas convencionalmente utilizadas, ele vem demonstrando resultados promissores em relação à praticidade técnica e à recuperação pós-operatória.

A vantagem da utilização do laser Nd-YAG é a promoção do rejuvenescimento através de método não-invasivo e não-ablativo. O sistema consiste na aplicação de nitrogênio líquido na forma de spray seguido do laser. A preparação da epiderme através do uso do criospray é a particularidade deste método, que propicia a proteção da camada epidérmica contra a ação do laser que posteriormente é aplicado, além de uma crioanestesia. Desta forma, os efeitos colaterais, como eritema, descamação, discromia, exsudação e constrangimento social, além de complicações como infecção, que são fatores inerentes aos lasers convencionais, serão minimizados.

O objetivo deste experimento é avaliar as alterações histológicas e morfométricas no tecido palpebral submetido à aplicação do laser Cool Touch 1,32nm Nd-YAG e comparar com o tecido controle.

\section{Material e método}

\section{Pacientes}

No período de janeiro (2000) a março (2001), realizou-se uma experiência com nove pacientes do sexo feminino que buscaram terapia de rejuvenescimento na Clínica de Cirurgia Plástica Estética e Reconstrutora Ltda. As idades variaram entre 38 e 55 anos e o principal critério de inclusão foi o prévio consentimento em participar do experimento. Após avaliação estética inicial, foi proposta para estas pacientes a aplicação do laser Nd-YAG em região palpebral direita, a fim de se obter resurfacing cutâneo, com conseqüente atenuação de rugas. Foram realizadas entre quatro e 11 sessões consecutivas, com intervalos de, apro- ximadamente, um mês. O número destas aplicações e seu intervalo e a energia do aparelho não estavam relacionados com a idade das pacientes, mas sim com a resposta clínica das rugas ao resurfacing facial e com a resposta dermoepidérmica aos danos ablativo e térmico residual provocados pela ação do laser a cada reavaliação clínica realizada entre uma sessão e outra. Após estes procedimentos, as pacientes foram submetidas a biópsia incisional na pálpebra direita, sendo que a área esquerda correspondeu à área de controle, livre de qualquer tipo de procedimento.

\section{Laser}

O laser utilizado foi o Nd-YAG, com comprimento de onda de 1.320 nanômetros (nm), energia de pulso de 56 a $306 \mathrm{~Hz}$ e com duração de 40 milissegundos (ms). A fluência foi de 20 a $30 \mathrm{~J} / \mathrm{cm}^{2}$, com grau de aquecimento subepidérmico de $42^{\circ} \mathrm{C}$ a $45^{\circ} \mathrm{C}$ e duração de resfriamento epidérmico de $30 \mathrm{~ms}$. Mensalmente, foram realizadas as aplicações do laser sobre a pálpebra direita das pacientes e, após 40 dias, foi realizada a biópsia palpebral bilateralmente.

\section{Amostra de pele}

Utilizou-se punch de $3 \mathrm{~mm}$ para a retirada do material para biópsia. Fixou-se o material com solução de formalina a $10 \%$. Este foi incluído, posteriormente, em um bloco de parafina, secionado em cortes com espessura de $4 \mu \mathrm{m}$, fixado em lâmina e corado com hematoxilina e eosina. Foram realizados três cortes para cada caso, tanto para a pálpebra direita (experimento) como para a esquerda (controle).

\section{Métodos de análise}

$\mathrm{Na}$ análise do material biopsiado, utilizaram-se a microscopia óptica comum e a morfometria.

\section{Microscopia óptica}

As regiões de epiderme, derme e anexos da lesão da região tratada (direita) foram comparadas com as da região controle (esquerda). As lâminas com artefatos foram desconsideradas para que isto não impedisse a análise morfométrica do experimento. Desta maneira, assinalou-se o melhor corte para a avaliação do material. Para esta análise utilizou-se microscópio binocular óptico Olympus BX40.

\section{Morfometria}

Os critérios morfométricos avaliados foram: medidas de espessura da epiderme, da área subepidérmica livre de lesão actínica, da zona de degeneração do colágeno e da 
espessura total da derme. Prepararam-se três cortes, sendo que em cada um foram feitas sete medidas. Mensuraram-se 20 medidas de cada critério em material colhido de ambas as pálpebras (experimento e controle). Posteriormente, através de métodos estatísticos, estimaram-se as diferenças morfométricas entre as camadas da pele da região que foram submetidas ao laser Nd-YAG (direita) e a região de controle (esquerda), não exposta ao laser.

\section{Resultados}

A análise histológica subjetiva não revelou diferenças qualitativas e quantitativas entre o grupo experimental e o grupo controle. Em vista do ocorrido, partiu-se para uma análise morfométrica mais objetiva.
$\mathrm{Na}$ área controle (pálpebra esquerda), as médias das medidas da espessura da epiderme variaram de 22,21 a $36,1 \mu \mathrm{m}$. Na área submetida à aplicação do laser (pálpebra direita), variaram de 21,27 a 55,28um (Figura 1). A espessura média da área subepidérmica livre de lesão actí-

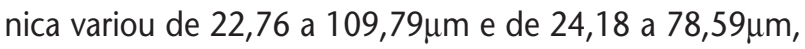
respectivamente (Figura 2). Na região controle, os valores médios da medida da espessura da degeneração do colágeno oscilaram de 208,06 a 392,98 $\mu \mathrm{m}$, enquanto que na região experimento, de 209 a 376,77 $\mu$ m (Figura 3). A espessura total da derme da pálpebra esquerda obteve média entre 530,74 e 846,16 $4 \mathrm{~m}$. Já a da pálpebra direita, 472,19 e 1.006,91 $\mu \mathrm{m}$ (Figura 4). Nas áreas submetidas à aplicação do laser $\mathrm{Nd}$-YAG, a espessura média da epiderme foi de $33,53 \mu \mathrm{m}$ e a pele controle foi de $29,61 \mu \mathrm{m}$

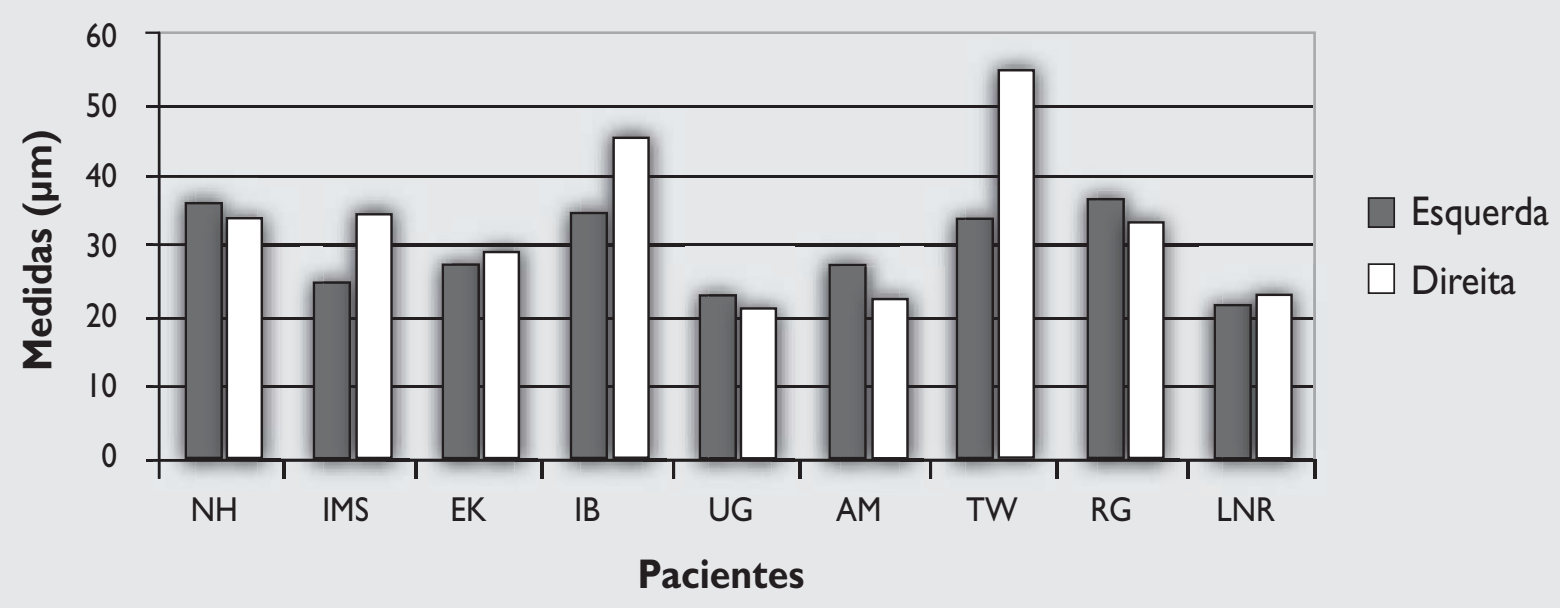

Figura 1 - Espessura média da epiderme em pálpebras direita (experimento) e esquerda (controle)

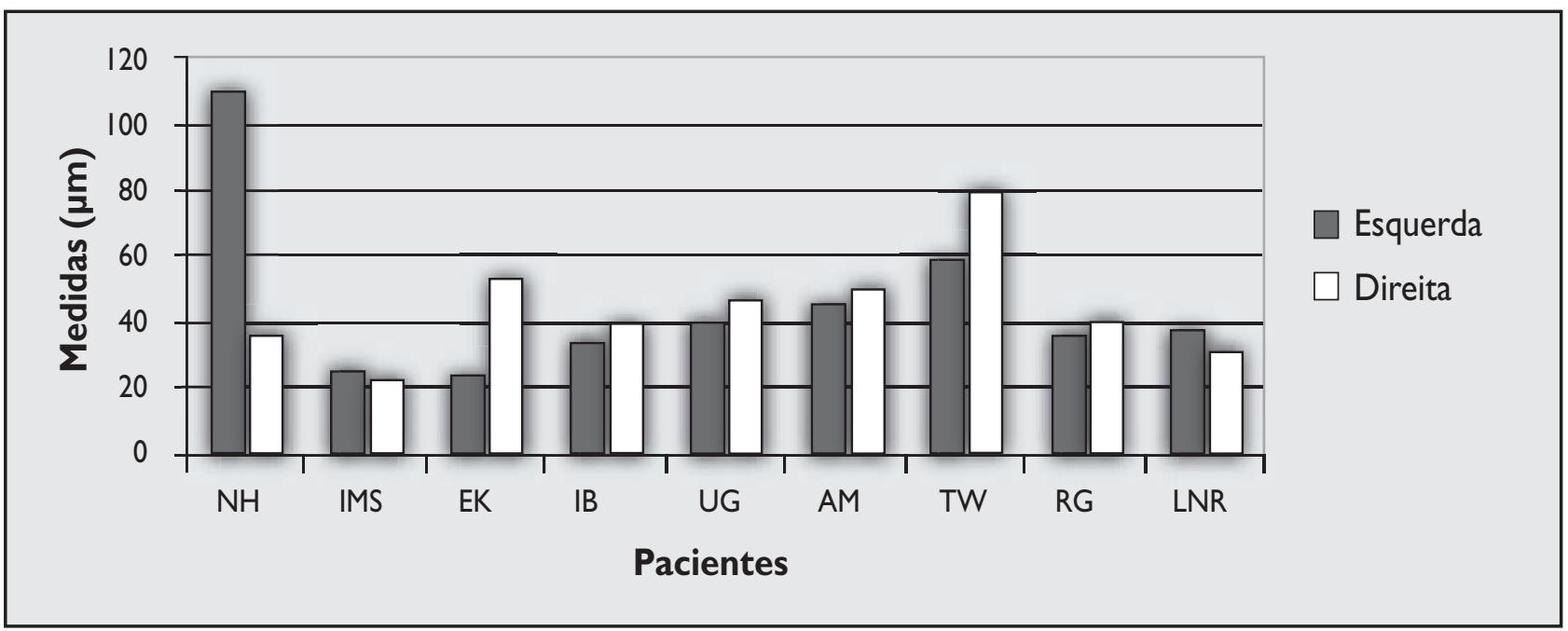

Figura 2 - Espessura média da área subepidérmica livre de lesão actínica das pálpebras direita (experimento) e esquerda (controle) 


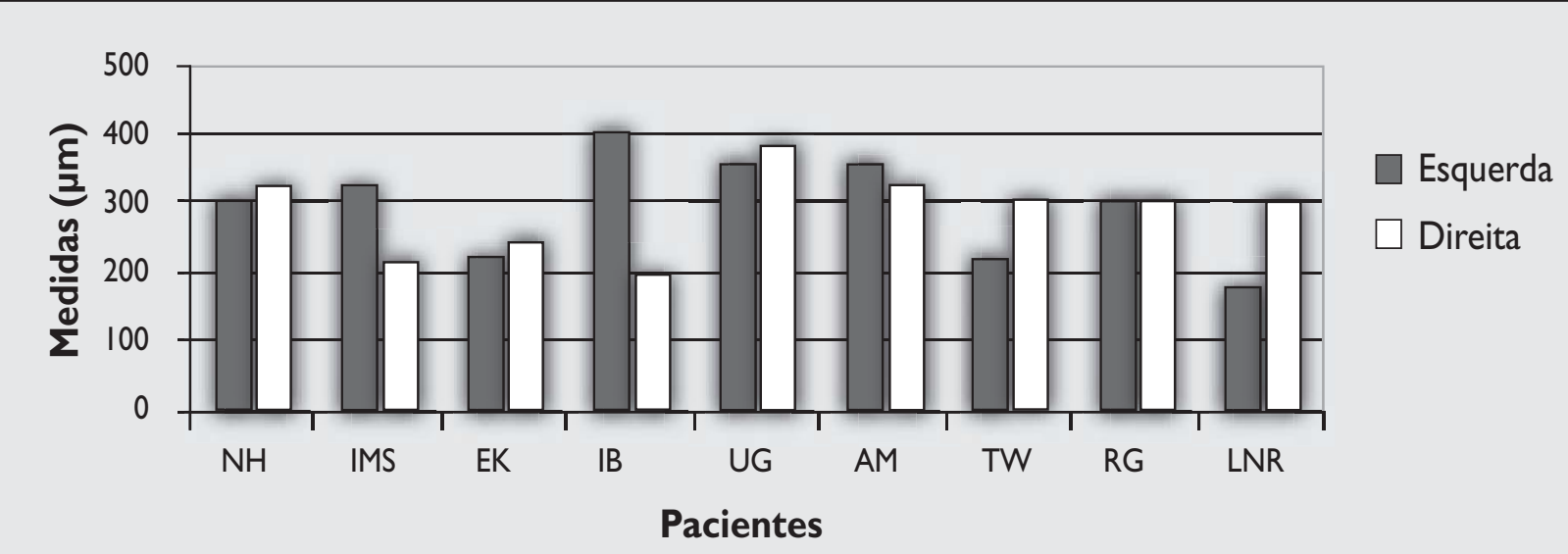

Figura 3 - Espessura média de degeneração do colágeno das pálpebras direita (experimento) e esquerda (controle)

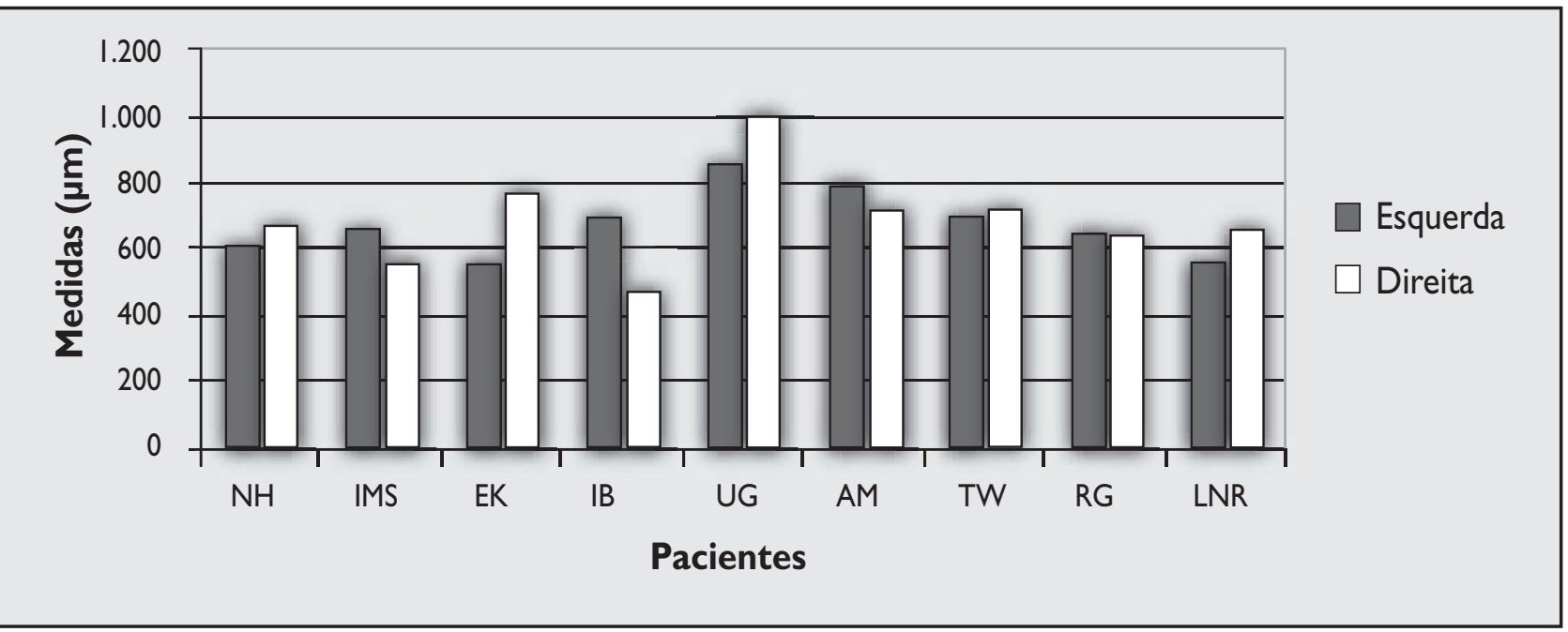

Figura 4 - Espessura média da derme completa das pálpebras direita (experimento) e esquerda (controle)

$(p=0,1099)$. A medida da área subepidérmica livre de lesão actínica, no lado do experimento, foi de, aproximadamente, $40,93 \mu \mathrm{m}$, e, no lado controle, de 36,27 $\mu \mathrm{m}(p=0,1373)$. A espessura da região de degeneração do colágeno na pálpebra que recebeu tratamento com o laser teve média de $293,54 \mu \mathrm{m}$, enquanto que na pálpebra controle, $292,22 \mu \mathrm{m}$ $(p=0,4835)$. No lado onde se aplicou o laser Nd-YAG, a espessura total da derme ficou em torno de $681,48 \mu \mathrm{m}$. No lado livre de procedimento, $664,14 \mu \mathrm{m}(p=0,3492)$ (Figura 5).

\section{Discussão}

A nova opção no tratamento para o rejuvenescimento é a aplicação do laser Nd-YAG 1.320nm. A vantagem deste sobre os convencionais é não produzir o dano de ablação na epiderme, pois, concomitantemente ao aquecimento da derme superficial, a fim de suscitar a necrose do colágeno, proporciona resfriamento da epiderme através de nitrogênio líquido, para evitar a ablação da mesma ${ }^{(6)}$. Assim, o efeito clínico do resurfacing é obtido, predominantemente, através do dano térmico residual que aquece os tecidos vizinhos, provocando desnaturação protéica e necrose coagulativa.

Indicou-se a aplicação do laser Cool Touch às nove pacientes da amostra, porque suas características clínicas condiziam com as ideais para um candidato ao tratamento do resurfacing. As características propostas eram: pele saudável e clara dos tipos I e II, rugas e cicatrizes leves, camada epidérmica minimamente danificada ou despigmentada e desejo das pacientes por uma discreta melhora estética.

Empregou-se o sistema de nitrogênio líquido associado ao laser Cool Touch, pois este, através do resfriamento 


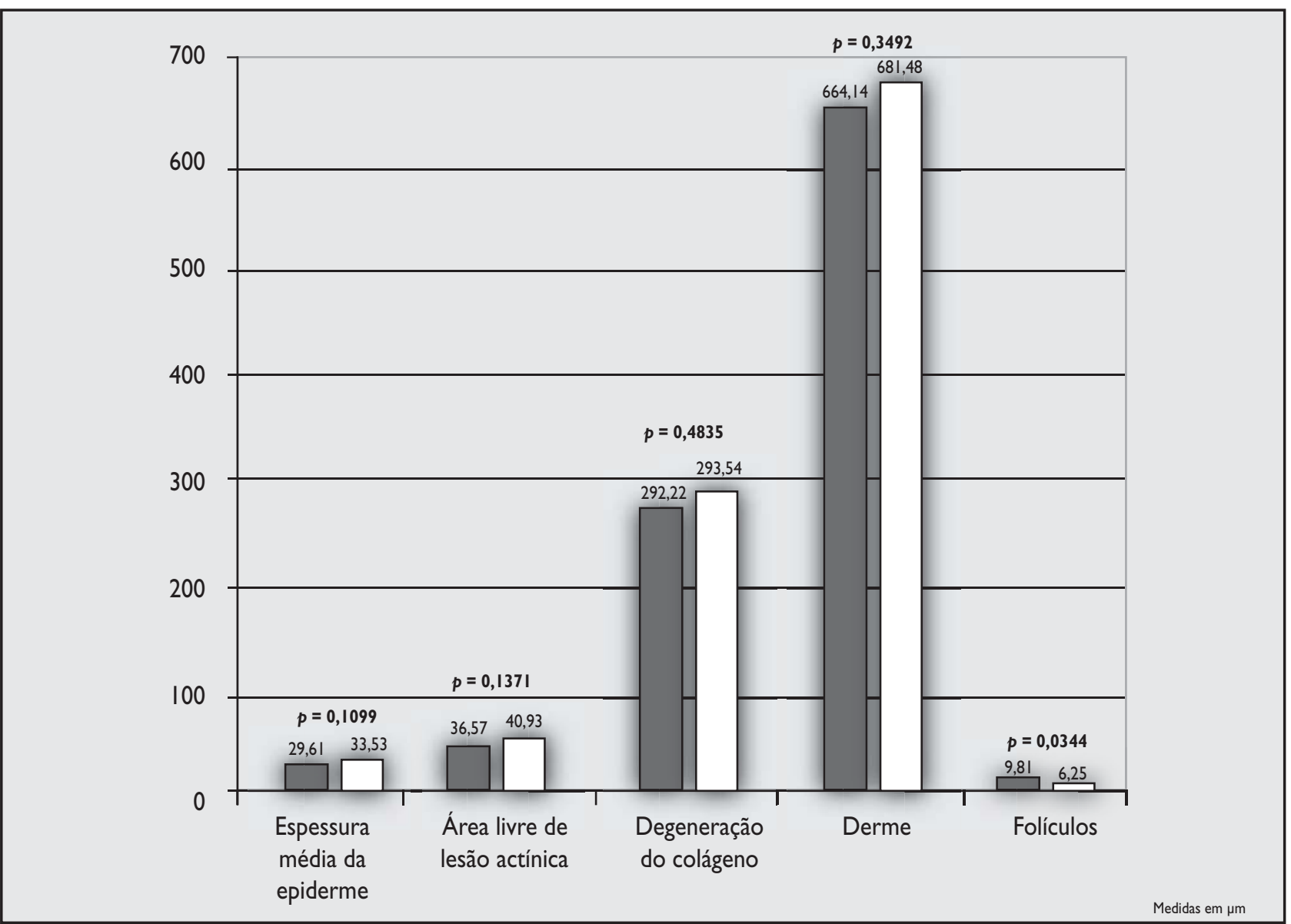

Figura 5 - Comparação quantitativa das variações morfométricas entre tecidos cutâneos submetidos a laser ND:YAG e tecidos cutâneos normais

epidérmico, proporciona efeitos anestésico e proteção térmica. O primeiro propiciou maior tolerância das pacientes com relação à aderência às aplicações. Já o segundo efeito possibilitou o uso de níveis mais altos de energia. Desta forma, este sistema minimizou ou, até mesmo, eliminou as complicações comuns associadas à terapia a laser no resurfacing, como eritema, edema, hiper/hipopigmentação, bolhas, descamação, além de infecção e cicatriz.

Essa evidência foi comprovada em trabalho realizado por Levy et $a l^{(5)}$. Eles observaram menor incidência de complicações e, quando presentes, estas apresentaram menor tempo de duração. Da amostra de 13 pacientes, três evoluíram para edema e hiperemia, sendo que, destas, uma apresentou descamação epidérmica dentro dos quatro primeiros dias pós-operatórios. Todas elas apresentaram eritema leve, sem alterações pigmentares. Entretanto uma paciente apresentou cicatriz escavada, relacionada à técnica de emprego do spray criogênico(5).

Vários autores já atestaram a eficácia e a segurança do emprego do nitrogênio líquido em combinação com o uso do laser não-ablativo Nd-YAG para o tratamento de rugas faciais. Uma amostra de 35 pacientes com idade entre 40 e 70 anos e tipos de pele I e II foi submetida à aplicação deste laser em região periorbital bilateral, num total de três procedimentos, com intervalo de duas semanas entre eles. As pacientes foram avaliadas após 12 e 24 semanas do pósoperatório, obtendo-se melhora, exclusivamente, no grupo que possuía rugas severas. Concluiu-se que a aplicação prévia do nitrogênio líquido propiciou bons resultados na morbidade pós-operatória dos pacientes. Através da ação de resfriamento do nitrogênio líquido, garantiu-se a proteção epidérmica, evitando-se a ablação provocada pelos outros tipos de laser, como o érbio e o $\mathrm{CO}_{2}{ }^{(4)}$.

Em outra revisão, alguns autores confirmaram a eficácia e a segurança do uso do laser Cool Touch, o qual combina a seletividade do comprimento de onda $(1.320 \mathrm{~nm})$ com o efeito térmico criogênico, demonstrando resultados clínicos eficazes e com poucas complicações, caso o controle térmico seja mantido ${ }^{(7)}$.

Neste estudo, a pele das pálpebras esquerda (controle) e direita (submetida ao procedimento) das pacientes foi 
avaliada morfologicamente aproximadamente 40 dias após o último dia de aplicação. Comparando-se à região controle, a microscopia óptica comum não revelou alterações significativas em epiderme, derme e anexos na região tratada. A morfometria minuciosa de cada critério avaliado também não apresentou diferenças relevantes. No entanto, houve nítida melhora clínica após o tratamento das lesões, manifestada igualmente pela satisfação das pacientes com o resultado.

Esta melhora clínica, não-acompanhada de alterações histológicas ou morfométricas, poderia ser justificada pelo curto tempo de acompanhamento destas pacientes antes da biópsia, que foi de apenas 40 dias no nosso experimento. Segundo alguns autores, são necessários seis meses de seguimento para se observar alterações histológicas nos tecidos submetidos à aplicação do laser Cool Touch. Goldberg, em seus dois estudos, investigou estas modificações em material biopsiado após seis meses do final do tratamento. Mesmo assim, a análise dos resultados destas experiências revelou alterações histológicas em apenas seis casos. Já na análise clínica, houve melhora em todos. Além disso, o autor concluiu que o laser suscitou a colagenização sem a ablação epidérmica, sendo esta a primeira responsável pela melhora clínica ${ }^{(2)}$. Após a aplicação de laser Nd-YAG em duas passadas com fluência de $7 \mathrm{~J} / \mathrm{cm}^{2}$, estudaram-se as alterações histológicas da pele de região infra-auricular antes do final do tratamento e três meses depois. Os tecidos biopsiados mostraram fibrose da camada da derme papilar superficial, com mudanças insignificativas na epiderme. Conclui-se, desta forma, que alterações morfológicas semelhantes, mas menos intensas, foram observadas com o uso do laser Nd-YAG(3).

Outra hipótese para a ausência de alterações histopatológicas em nosso estudo pode ser a quantidade de energia acumulada em cada paciente no final do experimento. Levy et al. ${ }^{(5)}$ utilizaram o laser Cool Touch numa fluência com a qual obtiveram alterações histológicas significativas, condizentes com a melhora clínica. A energia acumulada utilizada em seu trabalho foi maior que a utilizada em nosso estudo, levando-nos a concluir que as alterações histológicas poderiam ser resultantes da quantidade de energia acumulada ao final do tratamento(5).

Outros autores realizaram estudo envolvendo dez pacientes que se submeteram a duas aplicações semanais do laser Nd-YAG 1.320nm por mais de quatro semanas. Posteriormente, elas foram analisadas com duas e seis semanas de seguimento. Houve neocolagenização dérmica em todos os casos, porém somente dois pacientes expressaram satisfação com os resultados estéticos obtidos. Os autores relatam que é preciso cautela na indicação do uso deste laser, sendo necessário expor as reais possibilidades de melhora caso se criem expectativas inatingíveis. Afirmaram que o uso deste procedimento pode ser um armamento coadjuvante das técnicas ablativas para o resurfacing ${ }^{(8)}$.

Desta forma, se as biópsias tivessem sido feitas após um maior período, alguma alteração histológica e morfométrica poderia ter sido notada.

Com relação ao método de avaliação, pode-se supor que, se a microscopia eletrônica fosse utilizada, as alterações mínimas que passaram desapercebidas pela microscopia óptica talvez pudessem ser comprovadas, colaborando, assim, para a melhora clínica.

\section{Conclusões}

Os parâmetros histológicos e morfométricos avaliados pela microscopia óptica após 40 dias da aplicação do laser Nd-YAG na pálpebra de humanos não sofreram alterações estatisticamente significativas quando comparados com os da pele normal.

Desta forma, este experimento ratificou a necessidade atual de ampliação e aprofundamento dos estudos que envolvem o emprego do laser $\mathrm{Nd}-\mathrm{YAG} 1.320 \mathrm{~nm}$ como método não-invasivo de rejuvenescimento facial, visando à otimização dos resultados até então obtidos.

\section{Referências}

I. GOLDBERG, D. J. Non-ablative subsurface remodeling: clinical and histologic evaluation of a 1.320nm Nd-YAG laser.) Cutan LaserTher, v. I, p. I53-7, 1999.

2. GOLDBERG, D. J. Full-fac nonablative dermal remodeling with a 1.320nm Nd-YAG laser. Dermatol Surg, v. 26, p. 915-8, 2000.
3. GOLDBERG, D. J.; SILAPUNT, S. Histologic evaluation of a Q-switched Nd-YAG laser in the nonablative treatment of wrinkles. Dermatol Surg, v. 27, p. 744-6, 200 I.

4. KELLY, K. M.; NELSON,J. S.; LASK, G. P. et al. Cryogen spray cooling in combination with nonablative laser treatment of facial rhytides. Arch Dermatol, v. I35, n. 6, p. 691-4, 1999 
5. LEVY,J.L.;TRELLES, M.; LAGARDE,J.M. et al.Treatment of wrinkles with the nonablative 1.320nm Nd-YAG laser. Annals of Plastic Surg, v. 47, n. 5, p. 482-8, 200 I.

6. NEWMAN, J. Nonablative laser skin tightening. Facial Plast Surg Clin North Am, v. 9, p. 343-9, 2001.
7. PHAM, R. T. Nonablative laser resurfacing. Facial Plast Surg Clin North Am, v. 9, p. 303-10, 2001

8.TRELLES, M. A.; ALLONES, I.; LUNA, R. Facial rejuvenation with a nonablative 1.320nm Nd-YAG laser: a preliminary clinical and histologic evaluation. Dermatol Surg, v. 27, p. I | |-6, 200 I. 